\title{
Pregnant women with COVID-19: the placental involvement and consequences
}

\author{
Shahrzad Aghaamoo ${ }^{1} \cdot$ Kamran Ghods $^{2} \cdot$ Mojgan Rahmanian $^{1}$
}

Received: 1 December 2020 / Accepted: 16 March 2021 / Published online: 19 April 2021

(c) The Author(s), under exclusive licence to Springer Nature B.V. 2021

\begin{abstract}
SARS-CoV-2, the leading cause of COVID-19 pandemic, was detected for the first time in Wuhan. In this study, we investigated the potential undesirable maternal and feto-neonatal consequences of COVID-19, and the related pathophysiological alterations in mother, neonate, and especially in the placenta as a vital organ, were reviewed. Also, the possibility of vertical transmission of virus and placental abnormalities were evaluated. The pregnant women were a vulnerable population for COVID-19, and several obstetric consequences were reported following SARS-CoV-2 infection. The higher risk of abruption, preterm labor, maternal death, stillbirth, intrauterine growth restriction, and newborns with fetal distress were adverse pregnancy and perinatal outcomes of COVID-19. Despite the ACE2 expression on placental components was confirmed, there is no agreement on the mother-child vertical transmission of this virus. Therefore, feto-neonatal consequences might be associated with placental abnormalities. The placental abnormalities are characterized by feto-maternal vascular malperfusion. Additionally, these adverse consequences lead to early termination of pregnancy in some cases, mostly via cesarean section. The pregnant women screening, coordination between healthcare personnel and neonatal unit, and infected women quarantine may decrease the risk of maternal and neonatal death after delivery.
\end{abstract}

Keywords SARS-CoV-2 · COVID-19 · Feto-neonatal consequences · Maternal consequences · Vertical transmission · Placental abnormalities

\section{Introduction}

In December 2019, the outbreak of coronavirus disease 2019 (COVID-19) was reported in Wuhan, China, which has rapidly been changed as pandemic and spread throughout the worldwide (Lai et al. 2020). The acute respiratory syndrome-coronavirus 2 (SARS-CoV-2), the leading cause of COVID-19, is a human coronavirus ( $\mathrm{HCoV})$, which belongs to the Coronaviridae family (Cabeça et al. 2013; Li

Mojgan Rahmanian

dr_rahmanian@semums.ac.ir

Shahrzad Aghaamoo

aghaamoo_shahrzad@semums.ac.ir

Kamran Ghods

kamran_ghods@semums.ac.ir

1 Research Center of Abnormal Uterine Bleeding, Semnan University of Medical Sciences, Semnan, Iran

2 Clinical Research Development Unit, Kowsar Educational, Research and Therapeutic Hospital, Semnan University of Medical Sciences, Semnan, Iran et al. 2020a). HCoVs are classified as follows: HCoV-OC43, HCoV-HKU1, HCoV-NL63, and HCoV-229E with mild symptoms and SARS-CoV (2003 outbreak), Middle East respiratory syndrome-CoV (MERS-CoV, 2012 outbreak), and SARS-COV-2 with severe symptoms (Munster et al. 2020). The rapid and silent transmission of SARS-COV-2 via asymptomatic patients is associated with the increased incidence of infection (Biscayart et al. 2020; Carlos et al. 2020; Kinross et al. 2020). This virus has a single-stranded and positive-sense RNA genome. Both SARS-CoV and SARS-COV-2 use a similar receptor, angiotensin-converting enzyme2 (ACE2) receptor, to enter the host cells (Hoffmann et al. 2020b). The genomic characteristics of SARS-COV-2 have $80-85 \%$ nucleotide homology to SARS-CoV (Hoffmann et al. 2020a). Additionally, binding both viruses to the ACE2 receptor is mediated by coronavirus spike (S)protein (Lukassen et al. 2020). Although ACE2 is highly expressed in the respiratory system (He et al. 2006), its presence in other organs such as heart, liver and kidney has been reported. This increases the risk of multi-organ failure in COVID-19 patients (Roca-Ho et al. 2017). 
The symptomatic adult patients with COVID-19 manifest dry cough, fever, myalgia, malaise, rarely sputum production, dyspnea, headache, and hospitalization (Adhikari et al. 2020; Du et al. 2020; McMichael 2020). Severe illness can be developed as dyspnea and hypoxemia, and eventually change as acute respiratory distress syndrome (ARDS) within 1 week following the onset of illness (Chen et al. 2020c). The higher mortality rate among COVID-19 patients is associated with progressive ARDS and subsequent multiorgan dysfunction, resulting in death (El Zowalaty and Järhult 2020; Shanmugaraj et al. 2020; Zhou et al. 2020a). Furthermore, the underlying conditions e.g., liver, kidney, cardiovascular disease, as well as malignant tumors, and old age (older than 50), are risk factors to worsen the prognosis of COVID-19 (Chen et al. 2020c; Cui et al. 2020).

Additionally, the data on the consequences of pregnancy in women with COVID-19 are limited. What is currently known is pregnant women are a vulnerable population at the risk of severe infections. At this time, there is lack of evidence on adverse effects of maternal SARS-CoV-2 infection on the fetus (Zhao et al. 2020). What is important is that fetuses have poor toleration for acidosis and hypoxemia, which lead to complications such as preterm labor (OmoAghoja 2014). Additionally, maternal COVID-19 effects on infant is limited, and associated with some adverse consequences such as stillbirth and miscarriage (Karimi-Zarchi et al. 2020a). Previously, findings of investigations showed that the risk of severe infection, mortality, and morbidity in the pregnant women with SARS and MERS were higher compared with the non-pregnant women (Wang et al. 2020b). The vertical transmission of COVID-19 from mother to fetus or child and its short and long-term consequences to fetus and neonate is still unknown (Wang et al. 2020b).

In a narrative review, we investigated the features of COVID-19 in pregnant women and its feto-neonatal consequences. To identify how the placenta can be involved in the feto-neonatal outcomes, its pathological features and possibility of vertical transmission of virus from this vital organ were reviewed. For this purpose, a detailed literature review was done in standard databases, such as the PUBMED, SCOPUS, Google Scholar, and the Web of Science to search all published peer-reviewed articles, which investigated maternal and feto-neonatal consequences of COVID19 , involvement of placenta as a vital organ, and mother-tochild vertical transmission of SARS-CoV-2. Initial search keywords were defined as SARS-CoV-2, COVID-19, placenta, angiotensin-converting enzyme-2 (ACE-2), sepsis, cytokine storm, etc.

\section{COVID-19 and pregnancy: maternal consequences}

Different respiratory infections such as influenza, SARS, and MERS has been associated with increasing the rate of intensive care unit (ICU) admission, mechanical ventilation, and death (Alfaraj et al. 2019; Gottfredsson 2008; Jamieson et al. 2009; Lam et al. 2004a; Mertz et al. 2019; Wong et al. 2004). SARS was related to the higher rate of some adverse consequences in pregnant women, e.g., disseminated intravascular coagulation (DIC), sepsis, kidney disease, neurological symptoms, and a longer period of hospitalization (Lam et al. 2004a, b; Robertson et al. 2004; Yudin et al. 2005). Due to the high sequence similarity of SARS-CoV-2 and SARS$\mathrm{CoV}$ (Zhou et al. 2020b), the same trend of SARS can be predicted for the pregnant cases with COVID-19. In initial studies, the evaluation of infected pregnant women with SARS-CoV-2 manifested the general symptoms of COVID19, e.g., fever, cough, sore throat, myalgia, diarrhea, malaise, and shortness of breath. In laboratory data, lymphopenia and enhanced levels of alanine aminotransferase (ALT) or aminotransferase (AST) were seen similarly. The computed tomography (CT) scans showed multiple ground-glass opacity (GGO) shadows in lungs with a high diagnostic value. This study was performed on a small sample and women were at the late stage of pregnancy (Chen et al. 2020a, d). In a preliminary analysis, similar findings were observed in 15 pregnant women with COVID-19 pneumonia. These pregnant cases had achieved good recovery without receiving antiviral drugs at the end of the study (Liu et al. 2020a). Infection with SARS-COV-2 increased the rate of hospitalization and also enhanced receiving mechanical ventilation among the pregnant women without affecting the mortality rate (Ellington et al. 2020). The infected pregnant women need the ICU admission five times and mechanical ventilation four times more than non-pregnant women with the similar death rate (Collin et al. 2020). Additionally, the severity of COVID-19 in pregnant women was mild in $86 \%$, severe in $9.3 \%$, and critical in $4.7 \%$ of disease, the same frequency described for the general population (Breslin et al. 2020). Nevertheless, it seems that infection of pregnant patients with SARS-CoV-2 can raise the risk of maternal mortality. The results of a multi-central adjudicated case series performed in Iran demonstrated that from nine pregnant women were detected with severe infection; 1/9 recovered after a long time of hospitalization, 1/9 reminded as ventilatordependent with severe illness, and 7/9 died (Alfaraj et al. 2019). Moreover, infection with SARS-CoV-2 in the 2 nd or 3rd trimester of pregnancy might increase the risk of death due to cardiopulmonary complications (Hantoushzadeh et al. 2020).

Notably, pregnant women are a vulnerable to respiratory pathogens due to the immunomodulatory situation 
and physiological adaptations, e.g., reduced respiratory volumes due to the diaphragm elevation and edema of respiratory tract mucosa. These alterations increase the tolerance of women to hypoxia (Kourtis et al. 2014; LoMauro and Aliverti 2015). Pneumonia (especially viral source) is considered to be an important cause of respiratory failure, and is attributed to the higher rate of morbidity and mortality among the pregnant patients (Berkowitz and LaSala 1990). Maternal pneumonia is accompanied by some complications, such as preterm premature rupture of the membranes (PPROM), placental abruption, and preterm labor, leading to fetal or maternal death (Getahun et al. 2006; Richey et al. 1994; Schwartz and Graham 2020). Furthermore, the obstetric outcomes of COVID-19 include anemia, PPROM, preterm labor, multi-organ dysfunction. The CS was the most common procedure for the delivery of the baby. The most common consequence was preterm labor (Banaei et al. 2020). The results of a rapid review showed that preterm labor was seen in $42 \%$ of women with COVID-19 (Mullins et al. 2020).

It has been recommended that the COVID-19 can be exaggerated via pregnancy related cardio-vascular alterations and immune responses (Zaigham and Andersson 2020). Moreover, the hyperinflammation due to enhanced levels of cytokines, particularly interleukin 6 (IL-6) IL-1 $\beta$, and IL-12, is ascoaiceted with multi-organ dysfunction in critically ill patients (Mokhtari et al. 2020). Therefore, severe COVID-19 can be improved via the termination of the pregnancy. Accordingly, in a case report, the termination of pregnancy led to the improvement of severe liver and coagulation abnormalities (Ronnje et al. 2020). On the other hand, increased levels of ACE2 in the kidney of pregnant rats may locally increase the overexpression and production of angiotensin-(1-7) in the kidney during pregnancy (Brosnihan et al. 2003), which can increase the risk of acute kidney disease (AKI) in SARS-CoV-2-positive pregnant women. The AKI was observed in a pregnant woman with COVID-19 (Taghizadieh et al. 2020). COVID19 is related to thrombotic events in the general population (Knight et al. 2020). Activation of coagulation pathways due to the cytokine storm and hyperinflammation can lead to local or systemic coagulation abnormalities and consequently affect several organs. Therefore, monitoring the D-dimers and fibrinogen levels should be evaluated in all hospitalized patients with COVID-19 (Mokhtari et al. 2020). During normal pregnancy, increased levels of haemostatic components (e.g., factor X, factors V, VII, plasmin, and von Willebrand factor) can increase thrombin production and intravascular inflammation, leading to thrombophilia (Robertson et al. 2006). These alterations may be implicated in the pathogenesis of SARS-CoV-2 infection (Ji et al. 2020). While the pregnancy procedure raises the risk of thromboembolic events, pregnant women with COVID-19 may have synergistic risk factors for thrombosis with associated mortality. This hypothesis was confirmed in a case report in which a woman at the gestation of 29 weeks with COVID-19 died because of the basilar artery embolism and pulmonary embolism in the lower lobe (Ahmed et al. 2020). Therefore, to avoid adverse maternal consequences following COVID19 , special programs should be provided to manage pregnant women. Maternal consequences were summarized in Fig. 1.

\section{COVID-19 and pregnancy: feto-neonatal consequences}

Maternal pneumonia leads to several adverse feto-neonatal consequences, e.g., intrauterine growth restriction (IUGR), intrauterine fetal demise, and fetal or neonatal death (Getahun et al. 2006; Schwartz and Graham 2020). The higher rates of preterm labor, stillbirth, and abortion due to viral pneumonia caused by other respiratory viruses, e.g., influenza virus A/H1N1 (2009) (Jamieson et al. 2009), SARSCoV (Wong et al. 2003, 2004), and MERS-CoV (Alserehi et al. 2016). Pneumonia in pregnant women could increase the risk of fetal complications, including preterm births, IUGR, LBW, and 5-min Apgar score lesser than 7 (Chen et al. 2012). In the initial researches on feto-neonatal consequences of COVID-19, there was no significant difference in the frequency of fetal distress, greenish amniotic fluid (meconium staining), preterm labor, and neonatal asphyxia in the comparison of adverse outcomes of neonates from women with COVID-19 compared with those who from healthy women (Zhang et al. 2020a). A study on nine infected patients with CS showed nine live-births, just mild enhanced levels of myocardial enzymes were recorded for 1/9 neonates (Chen et al. 2020b). Also, no neonatal complications such as asphyxia, neonatal death, stillbirth, or miscarriage were recorded (Liu et al. 2020a).

However, in cases reports, a case of stillbirth (Liu et al. 2020c) and newborns with fetal distress with ICU admission (Chen et al. 2020a; Zhu et al. 2020) from COVID-19 women were reported. The most common outcome was fetal distress (Banaei et al. 2020). The feto-neonatal outcomes such as reduced fetal movement, prematurity, fetal distress, small for gestational age, LBW, asphyxia, stillbirth were recorded (Banaei et al. 2020; Liu et al. 2020b). Due to insufficient information, different infection duration, severe symptoms, and different immune responses of pregnant women, the interpretation of studies finding and determination of the causal link between neonatal complication and COVID-19 infection are not possible. On the other hand, a growing body of evidence suggests that the intrapartum may result in neonatal outcomes (Dior et al. 2016). Although the adverse fetoneonatal effects of COVID-19 have been proven, the exact mechanisms are not well-known. The direct or the indirect of SARS-CoV-2 may lead to these feto-neonatal effects. 


\section{COVID-19 and Pregnancy}

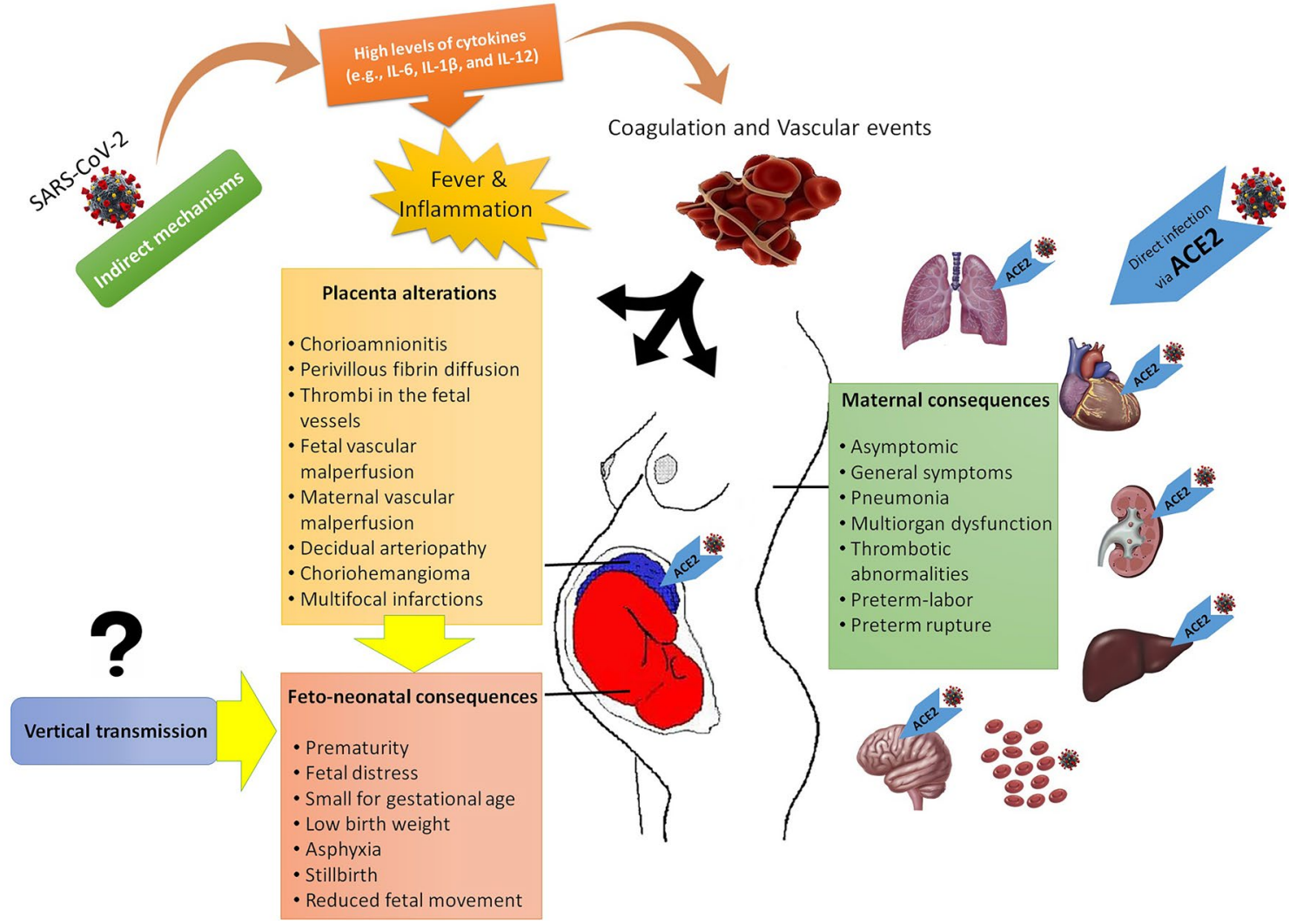

Fig. 1 COVID-19 and pregnancy. Maternal and feto-neonatal consequences and several pathological features of placenta. IL Interleukin, ACE2 angiotensin-converting enzyme 2

The question is that is there any possibility of mother-child vertical transmission of SARS-COV-2. Otherwise, the most important cause may be related to indirect effects of the virus by induction of pathological events inside the placenta. Feto-neonatal consequences were summarized in Fig. 1.

\section{COVID-19 and pregnancy: mother-child vertical transmission of the virus}

The neonates from SARS-CoV-2-positive women were positive for virus $16 \mathrm{~h}$ (Alzamora et al. 2020), $30 \mathrm{~h}$ (Zhang et al. 2020b), and $36 \mathrm{~h}$ (Wang et al. 2020a) after delivery. While the infection of neonates with SARS-CoV-2 was reported on the first day of life after delivery (Yu et al. 2020; Zeng et al. 2020b), it is not clear whether the source of the infection was from the mother or from the environment. In most studies, the neonates were separated from the mother after birth to reduce the chance of transmission. However, there is inadequate data regarding the separation of the baby form the mother (Poon et al. 2020).
The majority of studies have confirmed no evidence for SARS-CoV-2 mother-to-child transmission (Karimi-Zarchi et al. 2020b; Li et al. 2020b; Liu et al. 2020a; Muhidin et al. 2020; Zhang et al. 2020a; Zhu et al. 2020). In a study in New York on 43 pregnant with COVID-19, there was no proven neonatal infection with SARS-CoV-2 based on the initial test on the first day of life (Breslin et al. 2020). Virological evaluations of a COVID-19 woman with miscarriage during the 2nd trimester demonstrated that there was no data to confirm the placental infection and vertical transmission (Baud et al. 2020). There is no data to confirm the presence of infected cells in the maternal-fetal interface was not proven, ensuring that the transmission of SARS-CoV-2 through the placenta to the fetus is poor (Zheng et al. 2020). No viral RNA of SARS-CoV-2 was detected in the neonatal throat swabs or umbilical cord blood, amniotic fluid, neonatal pharynx swab, breast milk of first lactation samples from patients at the late stages of pregnancy. A well, there was a lack of data to confirm the intrauterine vertical transmission of the virus. Since the vaginal swabs were not collected, it was unknown 
whether SARS-CoV-2 infection could be related to vaginal delivery (Chen et al. 2020a, d). Besides, there was no agreement about the vertical transmission of SARS-CoV-2 in an infant at $30 \mathrm{~h}$ of age who was diagnosed for COVID-19 in Wuhan Children's Hospital (Jiatong and Wenjun 2020). Moreover, The results of a study in China showed that the origin of infection in the neonates was related to mother, as there were a strict infection control and preventive strategies during childbirth (Zeng et al. 2020b). In another study, the presence of SARS-CoV-2 was not confirmed in the serum or throat swab of six newborns from six mothers with COVID19 via RT-PCR test. However, the virus-specific antibodies (IgG in five and IgM in two infants) were identified in neonatal blood sera (Zeng et al. 2020a). Although IgG can pass through the placenta at the end of the 2nd trimester (Kohler and Farr 1966), IgM with a large macromolecular structure is not common to across the placenta. It might be secreted in the infant in response to viral infection, transmitted from the placenta (Irving et al. 2000). Furthermore, the positive result of PCR $16 \mathrm{~h}$ after CS delivery (with lower risk of disease) increases the probability of vertical transmission (Alzamora et al. 2020). Consequently, the maternal-to-neonatal vertical transmission of COVID-19 via the placenta is controversial. The vertical transmitting via breastfeeding or breast milk has not been proven. However, close contact with the mother or respiratory droplets during breastfeeding can infect the neonates (Rasmussen et al. 2020; She et al. 2020). Besides, more evaluations on a large number of pregnant women are needed to answer the question about the possible vertical transmission of SARS-CoV-2.On the other hand, the presence of feto-neonatal adverse outcomes of pregnancy from mothers with COVID-19 such as stillbirth, neonates with fetal distress, or requiring ICU admission (Chen et al. 2020a; Liu et al. 2020c; Zhu et al. 2020) suggests the potential evidence of SARS-CoV-2-induced placental pathology.

\section{COVID-19 and pregnancy: the role of the placenta}

The placenta has an essential role in modulating the immune response in several viral infections (PrabhuDas et al. 2015). Some viruses can cross the placental barrier and induce some associated severe fetal malformations (Antoniou et al. 2020; Lee et al. 2019). In SARS-CoV-2 infection, the viral RNA was not detected in the placenta (Chen et al. 2020a; Fan et al. 2020; Mulvey et al. 2020; Shanes et al. 2020). In contrast, placenta samples from the vast majority of cases were positive for SARS-CoV-2 (Hosier et al. 2020; Patanè et al. 2020; Shanes et al. 2020). To cross the virus from the placenta, it should bind to its specific receptor, ACE2. The enhanced expression and activation of ACE2 in the placenta, uterus, and kidney were confirmed during the pregnancy (Levy et al. 2008). In another study, angiotensin-(1-7) and ACE2 were detected in the syncytiotrophoblast of the subplacenta, labyrinthine placenta, giant cells, interlobium, syncytial sprouts, syncytial streamers, endothelium, and myometrium in the pregnant guinea-pig, indicating the role of angiotensin-(1-7) and ACE2 proteins in vascular remodeling, decidualization, trophoblast invasion, regulation of placental flow, and integration of uteroplacental vasodilatory network ( $\mathrm{Li}$ et al. 2020c). Moreover, the lower expression of ACE2 mRNA was reported in all cells differentiated from decidua and placenta from the early phases of pregnancy. But, the higher expression was related to the decidual perivascular cells (Zheng et al. 2020). By focusing on placental syncytium, the human placenta was reported to provide a structural and immunosuppressive defense against SARS-CoV-2. Structurally, it acts as a potent physical barrier and uses modulatory strategies (e.g., regulating the signaling pathways of interferon type III and the nuclear factor- $\mathrm{KB}$ and microRNA-mediating autophagy) against pathogens (Kreis et al. 2020). Therefore, the chance of virus transmission from mother to fetus decreases. ACE2 knockout mice were associated with uterine artery dysfunction in pregnant and subsequent decreased umbilical blood flow velocity and placental hypoxia (Yamaleyeva et al. 2015). These findings confirm the importance of ACE2 during pregnancy that may raise the risk of mother-to-child vertical transmission of SARS-CoV-2 or placental dysfunction.

The presence of diverse inflammatory cells of innate immune system including natural killer cells (70\%), CD4 T cells $(15 \%)$, and decidual macrophages $(15 \%)$ in the decidua basalis as the maternal component of placenta was proven (Wong et al. 2021). This makes an immunological barrier to the entry of pathogens and can protect the neonates against the SARS-CoV-2 infection (Carsetti et al. 2020). Nevertheless, the pathological alterations of the placenta following COVID-19 in pregnant women can lead to feto-neonatal consequences. It has been reported that chronic inflammation result from viral infections can induce some placental lesions characterized by the infiltration of plasma cells, lymphocytes, and, or macrophages. These lesions include chronic chorioamnionitis, villitis, and chronic deciduitis (Kim et al. 2015).

Chorioamnionitis with impacts on chorioamniotic membranes was detected in the placental samples of a pregnant woman with COVID-19 (Rashan et al. 2020). The histomorphological changes of the placenta have already been evaluated in several studies. The perivillous fibrin diffusion, presence of thrombi in the fetal vessels and induced vascular malperfusion, maternal vascular malperfusion, decidual arteriopathy choriohemangioma, and multi-focal infarctions were described for placenta from mother with SARS-CoV-2 infection (Hosier et al. 2020; Mulvey et al. 2020; Shanes et al. 2020). During the SARS pandemic, the pathological evaluation of the placenta have revealed the enhanced levels of intervillous and sub-chorionic fibrin, 
confirming the presence of abnormal maternal blood flow to the placenta ( $\mathrm{Ng}$ et al. 2004). Enhanced prevalence of feto-maternal vascular malperfusions due to a systemic inflammatory or hypercoagulable state result in oxygenation abnormalities related to the adverse perinatal consequences (Shanes et al. 2020). Therefore, the pathological features of placenta indicate that placenta is a susceptible organ to the maternal COVID-19. These abnormalities could be due to maternal comorbidities such as hypertension, preeclampsia, and gestational diabetes in many cases. Thus, there is a critical need for systematic studies to determine the prevalence of infection and replication of SARS-CoV-2 in the placenta and its association with placenta abnormalities (Fig. 1).

\section{Conclusions}

In summary, the symptoms of COVID-19 in pregnant women were similar with the general population; but pregnancy may increase the risk of ICU admission and mechanical ventilation requirement. Additionally, the COVID-19 may increase the frequency of abruption, PPROM, preterm labor, and maternal death, stillbirth, IUGR, newborns with fetal distress, or admitted to the ICU. The adverse feto-neonaltal consequences of COVID19 might be associated with placental dysfunctions. While throat swabs of some newborns were positive, there is no data to confirm the mother-to-child vertical transmission of SARS-CoV-2. More investigations should be performed to assess the risk of vertical transmission and its effects on feto-neonatal outcomes. Currently, no specific recommendations have been developed to evaluate or manage this vulnerable population against COVID-19. Also, the risk-benefit of antiviral therapy in pregnant women should be evaluated by the physicians. Overall, close coordination and collaboration between midwifery and neonatal unit are needed to manage the maternal and feto-neonatal outcomes following infection. Accordingly, a program should be developed in hospitals to implement strict infection control measures and screen pregnant women, quarantine infected women, and monitor neonates closely at the risk of COVID-19.

Author contributions SA and MR conceived of the presented idea. SA, $\mathrm{KG}$, and MR equally participated in drafting the article. SA and MR participated in revising it critically for important intellectual content. SA, KG, and MR gave final approval of the version to be submitted and any revised version.

Funding No funding to declare.

\section{Declarations}

Conflict of interest The authors declare that they have no conflict of interest.

Consent to publish N/A.

Informed consent N/A.

Research involving human participants and/or animals N/A.

\section{References}

Adhikari SP et al (2020) Epidemiology, causes, clinical manifestation and diagnosis, prevention and control of coronavirus disease (COVID-19) during the early outbreak period: a scoping review. Infect Dis Poverty 9:29. https://doi.org/10.1186/ s40249-020-00646-X

Ahmed I, Azhar A, Eltaweel N, Tan BK (2020) First Covid-19 maternal mortality in the UK associated with thrombotic complications. Br J Haematol. https://doi.org/10.1111/bjh.16849

Alfaraj SH, Al-Tawfiq JA, Memish ZA (2019) Middle East Respiratory Syndrome Coronavirus (MERS-CoV) infection during pregnancy: report of two cases \& review of the literature. J Microbiol Immunol Infect 52:501-503. https://doi.org/10.1016/j.jmii.2018. 04.0052018.04.005

Alserehi H, Wali G, Alshukairi A, Alraddadi B (2016) Impact of Middle East Respiratory Syndrome coronavirus (MERS-CoV) on pregnancy and perinatal outcome. BMC Infect Dis 16:1-4

Alzamora MC, Paredes T, Caceres D, Webb CM, Valdez LM, La Rosa M (2020) Severe COVID-19 during pregnancy and possible vertical transmission. Am J Perinatol 37:861

Antoniou E et al (2020) Zika virus and the risk of developing microcephaly in infants: a systematic review. Int J Environ Res Public Health. https://doi.org/10.3390/ijerph17113806

Banaei $\mathrm{M}$ et al (2020) Obstetrics and neonatal outcomes in pregnant women with covid-19: a systematic review Iranian. J Public Health 49:38-47

Baud D, Greub G, Favre G, Gengler C, Jaton K, Dubruc E, Pomar L (2020) Second-trimester miscarriage in a pregnant woman with SARS-CoV-2. Infect JAMA 323:2198-2200. https://doi.org/10. 1001/jama.2020.7233

Berkowitz K, LaSala A (1990) Risk factors associated with the increasing prevalence of pneumonia during pregnancy. Am J Obstet Gynecol 163:981-985. https://doi.org/10.1016/0002-9378(90) 91109-p

Biscayart C, Angeleri P, Lloveras S, Chaves T, Schlagenhauf P, Rodríguez-Morales AJ (2020) The next big threat to global health? 2019 novel coronavirus (2019-nCoV): What advice can we give to travellers? Interim recommendations January 2020, from the Latin-American society for Travel Medicine (SLAMVI) Travel medicine and infectious disease 33:101567 https://doi.org/10. 1016/j.tmaid.2020.101567

Breslin N et al (2020) COVID-19 infection among asymptomatic and symptomatic pregnant women: two weeks of confirmed presentations to an affiliated pair of New York City hospitals. Am J Obstetr Gynecol MFM 2:100118. https://doi.org/10.1016/j. ajogmf.2020.100118

Brosnihan KB et al (2003) Enhanced renal immunocytochemical expression of ANG-(1-7) and ACE2 during pregnancy. Hypertension 42:749-753

Cabeça TK, Granato C, Bellei N (2013) Epidemiological and clinical features of human coronavirus infections among different 
subsets of patients. Influenza Other Respir Viruses 7:10401047. https://doi.org/10.1111/irv.12101

Carlos WG, Dela Cruz CS, Cao B, Pasnick S, Jamil S (2020) Novel Wuhan (2019-nCoV) coronavirus. Am J Respir Crit Care Med 201:7-8

Carsetti R, Quintarelli C, Quinti I, Mortari EP, Zumla A, Ippolito G, Locatelli F (2020) The immune system of children: the key to understanding SARS-CoV-2 susceptibility? Lancet Child Adolescent Health 4:414-416

Chen Y-H, Keller J, Wang I-T, Lin C-C, Lin H-C (2012) Pneumonia and pregnancy outcomes: a nationwide population-based study. Am J Obstet Gynecol 207:288(e281-288. e287)

Chen $\mathrm{H}$ et al (2020a) Clinical characteristics and intrauterine vertical transmission potential of COVID-19 infection in nine pregnant women: a retrospective review of medical records. Lancet 395:809-815. https://doi.org/10.1016/s0140-6736(20)30360-3

Chen $\mathrm{H}$ et al (2020b) Clinical characteristics and intrauterine vertical transmission potential of COVID-19 infection in nine pregnant women: a retrospective review of medical records. Lancet 395:809-815. https://doi.org/10.1016/S0140-6736(20)30360-3

Chen $\mathrm{N}$ et al (2020c) Epidemiological and clinical characteristics of 99 cases of 2019 novel coronavirus pneumonia in Wuhan, China: a descriptive study. Lancet 395:507-513. https://doi. org/10.1016/s0140-6736(20)30211-7

Chen S et al (2020d) Pregnancy with new coronavirus infection: clinical characteristics and placental pathological analysis of three cases . Chin J Pathol 49:418-423. https://doi.org/10. 3760/cma.j.cn112151-20200225-00138

Collin J, Byström E, Carnahan A, Ahrne M (2020) Pregnant and postpartum women with SARS-CoV-2 infection in intensive care in Sweden. Acta Obstet Gynecol Scand. https://doi.org/ 10.1111/aogs.13901

Cui $\mathrm{P}$ et al (2020) Clinical features and sexual transmission potential of SARS-CoV-2 infected female patients: a descriptive study in Wuhan, China medRxiv

Dior UP et al (2016) Very high intrapartum fever in term pregnancies and adverse obstetric and neonatal outcomes. Neonatology 109:62-68

Du Z, Wang L, Cauchemez S, Xu X, Wang X, Cowling BJ, Meyers LA (2020) Risk for transportation of coronavirus disease from Wuhan to other cities in China. Emerg Infect Dis 26:1049

El Zowalaty ME, Järhult JD (2020) From SARS to COVID-19: a previously unknown SARS-related coronavirus (SARS-CoV-2) of pandemic potential infecting humans: call for a one health approach. One Health 9:100124. https://doi.org/10.1016/j.onehlt.2020.100124

Ellington S et al (2020) Characteristics of Women of Reproductive Age with Laboratory-Confirmed SARS-CoV-2 Infection by Pregnancy Status - United States, January 22-June 7, 2020 MMWR 69:769-775 https://doi.org/10.15585/mmwr.mm692 $5 \mathrm{a} 1$

Fan C et al (2020) Perinatal transmission of COVID-19 associated SARS-CoV-2: should we worry? Clin Infect Dis. https://doi.org/ 10.1093/cid/ciaa226

Getahun D, Ananth CV, Peltier MR, Smulian JC, Vintzileos AM (2006) Acute and chronic respiratory diseases in pregnancy: associations with placental abruption. Am J Obstet Gynecol 195:1180-1184. https://doi.org/10.1016/j.ajog.2006.07.027

Gottfredsson M (2008) The Spanish flu in Iceland 1918. Lessons in medicine history. Laeknabladid 94:737-745

Hantoushzadeh S et al (2020) Maternal death due to COVID-19. Am J Obstet Gynecol 223:109

$\mathrm{He} \mathrm{L}$ et al (2006) Expression of elevated levels of pro-inflammatory cytokines in SARS-CoV-infected ACE2+ cells in SARS patients: relation to the acute lung injury and pathogenesis of. SARS J Pathol 210:288-297. https://doi.org/10.1002/path.2067
Hoffmann M et al (2020a) SARS-CoV-2 cell entry depends on ACE2 and TMPRSS 2 and is blocked by a clinically proven protease inhibitor. Cell

Hoffmann M et al (2020b) SARS-CoV-2 cell entry depends on ACE2 and TMPRSS2 and is blocked by a clinically proven. Protease Inhibitor Cell 181:271-280.e278. https://doi.org/10.1016/j.cell. 2020.02.052

Hosier H et al (2020) SARS-CoV-2 infection of the placenta. J Clin Invest 130:4947-4953. https://doi.org/10.1172/jci139569

Irving W et al (2000) Influenza virus infection in the second and third trimesters of pregnancy: a clinical and seroepidemiological study BJOG. Int J Obstet Gynaecol 107:1282-1289

Jamieson DJ et al (2009) H1N1 2009 influenza virus infection during pregnancy in the USA. Lancet 374:451-458

Ji H-L, Zhao R, Matalon S, Matthay MA (2020) Elevated plasmin (ogen) as a common risk factor for COVID-19 susceptibility. Physiol Rev

Jiatong S, Wenjun L (2020) Epidemiological characteristics and prevention and control measures of Corona Virus Disease 2019 in children. J Trop Med 20:153-156

Karimi-Zarchi M et al (2020a) Vertical transmission of coronavirus disease 19 (COVID-19) from infected pregnant mothers to neonates: a review. Fetal Pediat Pathol 1-5

Karimi-Zarchi M et al (2020b) Vertical transmission of coronavirus disease 19 (COVID-19) from Infected pregnant mothers to neonates: a review. Fetal Pediat Pathol 39:246-250.https://doi.org/ 10.1080/15513815.2020.17471202020.1747120

Kim CJ, Romero R, Chaemsaithong P, Kim J-S (2015) Chronic inflammation of the placenta: definition, classification, pathogenesis, and clinical significance. Am J Obstet Gynecol 213:S53-S69. https://doi.org/10.1016/j.ajog.2015.08.041

Kinross P, Suetens C, Dias JG, Alexakis L, Wijermans A, Colzani E, Monnet DL (2020) Rapidly increasing cumulative incidence of coronavirus disease (COVID-19) in the European Union/ European Economic Area and the United Kingdom, 1 January to 15 March 2020. Eurosurveillance 25:2000285

Knight $\mathrm{M}$ et al (2020) Characteristics and outcomes of pregnant women admitted to hospital with confirmed SARS-CoV-2 infection in UK: national population based cohort study. BMJ 369

Kohler PF, Farr RS (1966) Elevation of cord over maternal IgG immunoglobulin: evidence for an active placental IgG transport. Nature 210:1070-1071. https://doi.org/10.1038/21010 $70 \mathrm{a} 0$

Kourtis AP, Read JS, Jamieson DJ (2014) Pregnancy and infection. N Engl J Med 370:2211-2218. https://doi.org/10.1056/NEJMr a1213566

Kreis NN, Ritter A, Louwen F, Yuan J (2020) A message from the human placenta: structural and immunomodulatory defense against SARS-CoV-2. Cells. https://doi.org/10.3390/cells90817 77

Lai C-C, Shih T-P, Ko W-C, Tang H-J, Hsueh P-R (2020) Severe acute respiratory syndrome coronavirus 2 (SARS-CoV-2) and coronavirus disease-2019 (COVID-19): the epidemic and the challenges. Int J Antimicrob Agents 55:105924-105924. https://doi. org/10.1016/j.ijantimicag.2020.105924

Lam CM et al (2004a) A case-controlled study comparing clinical course and outcomes of pregnant and non-pregnant women with severe acute respiratory syndrome. BJOG 111:771-774. https:// doi.org/10.1111/j.1471-0528.2004.00199.x

Lam CM et al (2004b) A case-controlled study comparing clinical course and outcomes of pregnant and non-pregnant women with severe acute respiratory syndrome. BJOG 111:771-774

Lee JK, Oh SJ, Park H, Shin OS (2019) Recent updates on research models and tools to study virus-host interactions at the placenta. Viruses 12:5 
Levy A, Yagil Y, Bursztyn M, Barkalifa R, Scharf S, Yagil C (2008) ACE2 expression and activity are enhanced during pregnancy. Am J Physiol Regul Integr Compar Physiol 295:R1953-R1961

Li G et al (2020a) Coronavirus infections and immune responses. J Med Virol 92:424-432. https://doi.org/10.1002/jmv.25685

Li Y et al (2020b) Lack of vertical transmission of severe acute respiratory syndrome coronavirus 2, China

Li Y, Zhou W, Yang L, You R (2020c) Physiological and pathological regulation of ACE2, the SARS-CoV-2 receptor. Pharmacol Res 157:104833

Liu D, Li L, Wu X, Zheng D, Wang J, Yang L, Zheng C (2020a) Pregnancy and perinatal outcomes of women with coronavirus disease (COVID-19) pneumonia: a preliminary analysis. Am J Roentgenol 215:127-132

Liu Y, Chen H, Tang K, Guo Y (2020b) Clinical manifestations and outcome of SARS-CoV-2 infection during pregnancy. J Infect

Liu Y, Chen H, Tang K, Guo Y (2020c) Clinical manifestations and outcome of SARS-CoV-2 infection during pregnancy. J Infect. https://doi.org/10.1016/j.jinf.2020.02.028

LoMauro A, Aliverti A (2015) Respiratory physiology of pregnancy. Physiol Masterclass Breathe (Sheff) 11:297-301. https://doi.org/ $10.1183 / 20734735.008615$

Lukassen S et al (2020) SARS-CoV-2 receptor ACE 2 and TMPRSS 2 are primarily expressed in bronchial transient secretory cells. EMBO J 39:e105114

McMichael TM (2020) COVID-19 in a long-term care facility-King County, Washington, February 27-March 9, 2020 MMWR Morbidity and Mortality Weekly Report 69

Mertz D, Lo CK-F, Lytvyn L, Ortiz JR, Loeb M (2019) Pregnancy as a risk factor for severe influenza infection: an individual participant data meta-analysis. BMC Infect Dis 19:683

Mokhtari T, Hassani F, Ghaffari N, Ebrahimi B, Yarahmadi A, Hassanzadeh $\mathrm{G}$ (2020) COVID-19 and multiorgan failure: a narrative review on potential mechanisms J Mol Histol 1-16

Muhidin S, Moghadam ZB, Vizheh M (2020) Analysis of maternal coronavirus infections and neonates born to mothers with 2019nCoV; a systematic review. Arch Acad Emerg Med 8

Mullins E, Evans D, Viner R, O’Brien P, Morris E (2020) Coronavirus in pregnancy and delivery: rapid review. Ultrasound Obstet Gynecol 55:586-592

Mulvey JJ, Magro CM, Ma LX, Nuovo GJ, Baergen RN (2020) Analysis of complement deposition and viral RNA in placentas of COVID-19 patients. Ann Diagn Pathol 46:151530. https://doi. org/10.1016/j.anndiagpath.2020.151530

Munster VJ, Koopmans M, van Doremalen N, van Riel D, de Wit E (2020) A novel coronavirus emerging in China: key questions for impact assessment. N Engl J Med 382:692-694. https://doi.org/ 10.1056/NEJMp2000929

Ng PC, Leung CW, Chiu WK, Wong SF, Hon EK (2004) SARS in newborns children. Biol Neonate 85:293-298. https://doi.org/ $10.1159 / 000078174$

Omo-Aghoja L (2014) Maternal and fetal Acid-base chemistry: a major determinant of perinatal outcome. Ann Med Health Sci Res 4:817. https://doi.org/10.4103/2141-9248.126602

Patanè L et al (2020) Vertical transmission of coronavirus disease 2019: severe acute respiratory syndrome coronavirus 2 RNA on the fetal side of the placenta in pregnancies with coronavirus disease 2019-positive mothers and neonates at birth. Am J Obstet Gynecol MFM 2:100145. https://doi.org/10.1016/j.ajogmf.2020. 100145

Poon LC et al (2020) ISUOG Interim Guidance on 2019 novel coronavirus infection during pregnancy and puerperium: information for healthcare professionals. Ultrasound Obstet Gynecol

PrabhuDas $M$ et al (2015) Immune mechanisms at the maternal-fetal interface: perspectives and challenges. Nat Immunol 16:328-334. https://doi.org/10.1038/ni.3131
Rashan N, Bahmani M, Direkvand-Moghadam A (2020) A case report of COVID-19 in a Pregnant woman with clinical manifestations of chorioamnionitis in Ilam. Iran Int J High Risk Behav Addict 9:e105178. https://doi.org/10.5812/ijhrba. 105178

Rasmussen SA, Smulian JC, Lednicky JA, Wen TS, Jamieson DJ (2020) Coronavirus Disease 2019 (COVID-19) and pregnancy: what obstetricians need to know. Am J Obstet Gynecol 222:415426. https://doi.org/10.1016/j.ajog.2020.02.017

Richey SD, Roberts SW, Ramin KD, Ramin SM, Cunningham FG (1994) Pneumonia complicating pregnancy. Obstet Gynecol 84:525-528

Robertson CA et al (2004) SARS and pregnancy: a case report. Emerg Infect Dis 10:345-348. https://doi.org/10.3201/eid1002.030736

Robertson L et al (2006) Thrombophilia in pregnancy: a systematic review. Br J Haematol 132:171-196

Roca-Ho H, Riera M, Palau V, Pascual J, Soler MJ (2017) Characterization of ACE and ACE2 expression within different organs of the NOD mouse. Int J Mol Sci 18:563. https://doi.org/10.3390/ ijms 18030563

Ronnje L, Länsberg J-K, Vikhareva O, Hansson S, Herbst A, Zaigham M (2020) Complicated COVID-19 in pregnancy: a case report with severe liver and coagulation dysfunction promptly improved by delivery

Schwartz DA, Graham AL (2020) Potential maternal and infant outcomes from (Wuhan) coronavirus 2019-nCoV infecting pregnant women: lessons from SARS, MERS, and other human coronavirus infections viruses $12 \mathrm{https}$ ://doi.org/10.3390/v12020194

Shanes ED, Mithal LB, Otero S, Azad HA, Miller ES, Goldstein JA (2020) Placental Pathology in COVID-19. Am J Clin Pathol 154:23-32. https://doi.org/10.1093/ajcp/aqaa089

Shanmugaraj B, Siriwattananon K, Wangkanont K, Phoolcharoen W (2020) Perspectives on monoclonal antibody therapy as potential therapeutic intervention for Coronavirus disease-19 (COVID-19). Asian Pacific J Allergy Immunol

She J, Liu L, Liu W (2020) COVID-19 epidemic: disease characteristics in children. J Med Virol

Taghizadieh A, Mikaeili H, Ahmadi M, Valizadeh H (2020) Acute kidney injury in pregnant women following SARS-CoV-2 infection: a case report from Iran. Respir Med Case Rep 30:101090 101090. https://doi.org/10.1016/j.rmcr.2020.101090

Wang S, Guo L, Chen L, Liu W, Cao Y, Zhang J, Feng L (2020a) A case report of neonatal 2019 coronavirus disease in China. Clin Infect Dis 71:853-857. https://doi.org/10.1093/cid/ciaa225

Wang S, Guo L, Chen L, Liu W, Cao Y, Zhang J, Feng L (2020b) A case report of neonatal 2019 coronavirus disease in China. Clin Infect Dis

Wong S, Chow K, De Swiet M (2003) Severe acute respiratory syndrome and pregnancy. BJOG 110:641

Wong SF et al (2004) Pregnancy and perinatal outcomes of women with severe acute respiratory syndrome. Am J Obstet Gynecol 191:292-297

Wong YP, Khong TY, Tan GC (2021) The Effects of COVID-19 on placenta and pregnancy. What do we know so far? Diagnostics 11:94

Yamaleyeva LM et al (2015) Uterine artery dysfunction in pregnant ACE2 knockout mice is associated with placental hypoxia and reduced umbilical blood flow velocity. Am J Physiol Endocrinol Metab 309:E84-E94

$\mathrm{Yu} \mathrm{N}$ et al (2020) Clinical features and obstetric and neonatal outcomes of pregnant patients with COVID-19 in Wuhan, China: a retrospective, single-centre, descriptive study. Lancet Infect Dis

Yudin MH, Steele DM, Sgro MD, Read SE, Kopplin P, Gough KA (2005) Severe acute respiratory syndrome in pregnancy. Obstet Gynecol 105:124-127. https://doi.org/10.1097/01.AOG.00001 51598.49129.de 
Zaigham M, Andersson O (2020) Maternal and perinatal outcomes with COVID-19: a systematic review of 108 pregnancies. Acta Obstet Gynecol Scand

Zeng H, Xu C, Fan J, Tang Y, Deng Q, Zhang W, Long X (2020a) Antibodies in infants born to mothers with COVID-19. Pneumonia JAMA 323:1848-1849. https://doi.org/10.1001/jama.2020.4861

Zeng L, Xia S, Yuan W, Yan K, Xiao F, Shao J, Zhou W (2020b) Neonatal early-onset infection with SARS-CoV-2 in 33 neonates born to mothers with COVID-19 in Wuhan, China. JAMA Pediat

Zhang L et al (2020a) Analysis of the pregnancy outcomes in pregnant women with COVID-19 in Hubei Province. Zhonghua fu chan ke za zhi 55:E009-E009

Zhang Z, Wang C, Gao C (2020b) Neonatal coronavirus expert confirmed at 30 hours of birth: vertical transmission from mother to infant

Zhao X, Jiang Y, Zhao Y, Xi H, Liu C, Qu F, Feng X (2020) Analysis of the susceptibility to COVID-19 in pregnancy and recommendations on potential drug screening. Eur J Clin Microbiol Infect Dis 39:1209-1220. https://doi.org/10.1007/s10096-020-03897-6
Zheng Q-L, Duan T, Jin L-P (2020) Single-cell RNA expression profiling of ACE2 and AXL in the human maternal-fetal interface. Reprod Dev Med 4:7

Zhou F et al (2020a) Clinical course and risk factors for mortality of adult inpatients with COVID-19 in Wuhan: a retrospective cohort study, China. Lancet

Zhou P et al (2020b) A pneumonia outbreak associated with a new coronavirus of probable bat origin. Nature 579:270-273

$\mathrm{Zhu} \mathrm{H}$ et al (2020) Clinical analysis of 10 neonates born to mothers with 2019-nCoV pneumonia. Transl Pediatr 9:51-60. https://doi. org/10.21037/tp.2020.02.06

Publisher's Note Springer Nature remains neutral with regard to jurisdictional claims in published maps and institutional affiliations. 